University of Nebraska - Lincoln

DigitalCommons@University of Nebraska - Lincoln

Faculty Papers and Publications in Animal

Science

Animal Science Department

March 1994

Estimates of Genetic Parameters for 320-Day Pelvic

Measurements of Males and Females and Calving Ease of 2-YearOld Females

\author{
L. A. Kriese \\ Auburn University \\ L. Dale Van Vleck \\ University of Nebraska-Lincoln, dvan-vleck1@unl.edu \\ K. E. Gregory \\ Roman L. Hruska US. Meat Animal Research Center, USDA-ARS, Clay Center, NE \\ K. G. Boldman \\ DeKalb Poultry Research, Inc. \\ Larry V. Cundiff \\ University of Nebraska-Lincoln, Icundiff2@unl.edu \\ See next page for additional authors
}

Follow this and additional works at: https://digitalcommons.unl.edu/animalscifacpub

Part of the Animal Sciences Commons

Kriese, L. A.; Van Vleck, L. Dale; Gregory, K. E.; Boldman, K. G.; Cundiff, Larry V.; and Koch, R. M., "Estimates of Genetic Parameters for 320-Day Pelvic Measurements of Males and Females and Calving Ease of 2-Year-Old Females" (1994). Faculty Papers and Publications in Animal Science. 254.

https://digitalcommons.unl.edu/animalscifacpub/254

This Article is brought to you for free and open access by the Animal Science Department at DigitalCommons@University of Nebraska - Lincoln. It has been accepted for inclusion in Faculty Papers and Publications in Animal Science by an authorized administrator of DigitalCommons@University of Nebraska - Lincoln. 


\section{Authors}

L. A. Kriese, L. Dale Van Vleck, K. E. Gregory, K. G. Boldman, Larry V. Cundiff, and R. M. Koch 


\title{
Estimates of Genetic Parameters for 320-Day Pelvic Measurements of Males and Females and Calving Ease of 2-Year-Old Females ${ }^{1}$
}

\author{
L. A. Kriese ${ }^{2}$, L. D. Van Vleck $^{3}$, K. E. Gregory, K. G. Boldman', \\ L. V. Cundiff, and R. M. Koch
}

Roman L. Hruska U.S. Meat Animal Research Center, ARS, USDA, Clay Center, NE 68933 and Department of Animal Science, University of Nebraska, Lincoln 68583-0908

\begin{abstract}
Records from 12 breed groups collected from 1983 to 1991, included in the Germ Plasm Utilization project at the U.S. Meat Animal Research Center, were analyzed separately by breed group and combined to estimate heritabilities and genetic correlations for 320-d male and female pelvic width, height, and area, and for 320-d male pelvic and female 2 -yr-old calving ease. Calving ease was analyzed as a trait of the dam using 1) actual and 2) binary scale calving ease scores with a covariate of calf birth weight. A bivariate animal model and derivative-free REML incorporating sparse matrix techniques were used. When breed groups were analyzed separately, heritability estimates of male and female 320 -d pelvic traits varied by breed group and sex. Average genetic correlations between male and female 320 -d pelvic width, pelvic height, and pelvic area were large and positive. When breed groups were combined ( $\mathrm{n}=$ 26,071 ), heritability estimates for 320 -d pelvic traits were moderate in size. Genetic correlations of $.68, .48$, and .61 , between male and female 320 -d pelvic width,
\end{abstract}

height, and area, respectively, suggest male and female pelvic traits are largely under the same genetic control but are correlated traits rather than the same trait. Heritability estimates for actual calving ease in 2-yr-olds ranged from .00 to .49 in separate breed group analyses, and from .00 to .37 for binary measures. When breed groups were combined, heritability was .11 for actual calving ease and was .09 on the binary scale. Genetic correlations by breed groups between 320-d male pelvic traits and calving ease of 2-yr-old females were variable. When breed groups were combined, genetic correlation estimates between 320-d male pelvic traits and actual calving ease of 2-yr-old females (on a 6-point scale) were negative and moderate as were genetic correlations between male 320-d pelvic traits and binary calving ease of 2-yr-old females. A bull one phenotypic SD above the mean in pelvic area would be expected to increase his daughters' average pelvic area by $1.30 \mathrm{~cm}^{2}$ and improve its calving ease score by .03 of a score compared with an average breed bull.

Key Words: Pelvic Traits, Calving, Heritability, Genetic Correlation, Animal Models

J. Anim. Sci. 1994. 72:1954-1963

\section{Introduction}

Dystocia is a major problem in the beef cattle industry that results in considerable economic loss. Price and Wiltbank (1978) concluded that dystocia in 2 -yr-old heifers was primarily caused by a disproportion between size of the calf and pelvic area in the

\footnotetext{
${ }^{1}$ Published as paper no. 10421, Journal Ser., Nebraska Agric. Res. Div., Univ. of Nebraska, Lincoln 68583-0908.

${ }^{2}$ Present address: Animal and Dairy Sciences, Auburn Univ., Auburn, AL 36849-5415.

${ }^{3}$ To whom correspondence should be addressed: A218 Animal Sciences, Lincoln.

${ }^{4}$ Present address: DeKalb Poultry Research, Inc., 3100 Sycamore Road, DeKalb, IL 60115.

Received June 21, 1993.

Accepted March 6, 1994.
}

dam. Studies examining yearling female pelvic width, height, and area have indicated moderate to high heritability estimates for these traits (Benyshek and Little, 1982; Morrison et al., 1986; Green et al., 1988; and Anderson et al., 1991). Naazie et al. (1991) reported favorable negative genetic correlations between calving ease scores in 2-yr-old heifers and pelvic width, height, and area measured in the heifers 6 mo later. These results raise the question of whether pelvic area could be used as a selection criterion for bulls to reduce dystocia in replacement heifers. Green et al. (1986) reported a genetic correlation of .61 between male and female pelvic area and concluded selection for increased male pelvic area should produce female progeny with larger pelvic areas.

The purposes of this study were first, to estimate heritabilities of and genetic correlations between 320-d pelvic width, height, and area in bulls and 
heifers to determine whether pelvic growth is under the same genetic control in both sexes and second, to estimate heritability for calving ease score of 2-yr-old females and determine the genetic relationships between calving ease and 320-d pelvic width, height, and area of bulls.

\section{Materials and Methods}

\section{Data Collection}

Data were collected from the Germ Plasm Utilization ( GPU) project at the U.S. Meat Animal Research Center (MARC). The GPU project consists of nine pure breeds of cattle and three composite populations. The nine pure breeds are Angus (A), Braunvieh (B), Charolais (C), Gelbvieh (G), Hereford (H), Limou$\sin (\mathbf{L})$, Pinzgauer ( $\mathbf{P})$, Red Poll ( $\mathbf{R})$, and Simmental (S). The three composite populations, MARC I, MARC II, and MARC III are composed of $1 / 4 \mathrm{~B}, 1 / 4 \mathrm{C}$, $1 / 4 \mathrm{~L}, 1 / 8 \mathrm{H}, 1 / 8 \mathrm{~A} ; 1 / 4 \mathrm{G}, 1 / 4 \mathrm{~S}, 1 / 4 \mathrm{H}, 1 / 4 \mathrm{~A}$; and $1 / 4$ $\mathrm{R}, 1 / 4 \mathrm{P}, 1 / 4 \mathrm{H}, 1 / 4 \mathrm{~A}$, respectively. Description of matings to establish these composite populations and breeding and management practices are described by Gregory et al. (1991).

Calves were weighed at birth, at mid-breeding season (end of AI breeding period), at weaning, and $28,84,140$, and $168 \mathrm{~d}$ postweaning. Height was measured at 28 and $168 \mathrm{~d}$ postweaning in both sexes. Pelvic width and height measurements were recorded $140 \mathrm{~d}$ postweaning in both intact males and in heifers at an average age of $320 \mathrm{~d}$ beginning in 1983 . Pelvic measurements were taken by two or three experienced technicians each year. From 1983 through 1985, measurements were taken by the Krautman-Litton Pelvic Meter (Jorgensen Laboratories, Loveland, CO). The Rice Pelvimeter (Lane Mfg., Denver, CO) was used after 1985. Pelvic area was determined as the product of pelvic width and pelvic height measurements.

All females were exposed for breeding. Females were retained if they were determined to be pregnant. Calving difficulty was subjectively evaluated using descriptive scores (i.e., 1 = no difficulty, 2 = little difficulty by hand, $3=$ little difficulty with calf jack, 4 $=$ slight difficulty with calf jack, $5=$ moderate difficulty with calf jack, $6=$ major difficulty with calf jack, $7=$ Caesarean birth, and $8=$ abnormal presentation). In analyses involving calving difficulty scores, scores of 7 and 8 were excluded because it was not known why caesarean sections were performed. Calves could have been too large to pass through the birth canal or abnormally presented or both. A total of 367 calving ease records were excluded. In addition, a binary scale representing the incidence of calving difficulty was created (scores 1 and $2=0$; scores 3,4 , 5 , and $6=1$ ).
General Form of

\section{Bivariate Animal Model}

Data were analyzed using a bivariate animal model. In this paper, a bivariate animal model is defined as a specialized form of a two-trait multipletrait animal model, where an animal produces a record for only one of the two traits. Therefore, the traits are connected only through numerator relationships. The general form of the bivariate animal model is as follows:

$$
\left[\begin{array}{l}
\mathrm{y}_{1} \\
\mathrm{y}_{2}
\end{array}\right]=\left[\begin{array}{ll}
\mathbf{X}_{1} & \mathbf{0} \\
\mathbf{0} & \mathbf{X}_{2}
\end{array}\right]\left[\begin{array}{l}
\mathrm{b}_{1} \\
\mathrm{~b}_{2}
\end{array}\right]+\left[\begin{array}{ll}
\mathbf{Z}_{1} & \mathbf{0} \\
\mathbf{0} & \mathbf{z}_{2}
\end{array}\right]\left[\begin{array}{l}
\mathrm{u}_{1} \\
\mathrm{u}_{2}
\end{array}\right]+\left[\begin{array}{l}
\mathrm{e}_{1} \\
\mathrm{e}_{2}
\end{array}\right]
$$

where

$$
\begin{aligned}
& \mathrm{y}_{1}\left(\mathrm{y}_{2}\right)=\text { is a vector of records for Trait } 1 \text { (Trait } \\
& \text { 2), } \\
& b_{1}\left(b_{2}\right)=a \text { vector of fixed effects for Trait } 1 \\
& \text { (Trait 2), } \\
& \mathrm{u}_{1}\left(\mathrm{u}_{2}\right)=\mathrm{a} \text { vector of random genetic animal ef- } \\
& \text { fects for Trait } 1 \text { (Trait 2) including } \\
& \text { animals without records, } \\
& \mathbf{e}_{1}\left(\mathrm{e}_{2}\right)=\text { is a vector of residual effects of Trait } 1 \\
& \text { (Trait 2), and } \\
& \mathbf{X}_{1}\left(\mathbf{X}_{2}\right),=\text { incidence matrices associating ele- } \\
& \mathbf{z}_{1}\left(\mathbf{z}_{2}\right) \text { ments of } \mathrm{b}_{1}\left(\mathrm{~b}_{2}\right) \text { and } \mathrm{u}_{1}\left(\mathrm{u}_{2}\right) \text { with } \\
& \text { records in } \mathrm{y}_{1}\left(\mathrm{y}_{2}\right) \text {. }
\end{aligned}
$$

The $E\left[y_{i}\right]=X_{i} b_{i}$, for $i=1,2$. The variance-covariance structure of the random elements in the bivariate animal model is as follows:

$$
\mathrm{V}\left[\begin{array}{l}
\mathrm{u}_{1} \\
\mathrm{u}_{2} \\
\mathrm{e}_{1} \\
\mathrm{e}_{2}
\end{array}\right]=\left[\begin{array}{llll}
\mathbf{A} \sigma_{\mathrm{a}_{1}}^{2} & \mathbf{A} \sigma_{\mathrm{a}_{1} \mathrm{a}_{2}} & 0 & 0 \\
\mathbf{A} \sigma_{\mathrm{a}_{1} \mathrm{a}_{2}} & \mathbf{A} \sigma_{\mathrm{a}_{2}}^{2} & 0 & 0 \\
0 & 0 & \mathrm{I} \sigma_{\mathrm{e}_{1}}^{2} & 0 \\
0 & 0 & 0 & \mathrm{I} \sigma_{\mathrm{e}_{2}}^{2}
\end{array}\right]
$$

where

$$
\begin{aligned}
\mathbf{A}= & \text { the numerator relationship matrix } \\
& \text { among all animals, including parents } \\
& \text { without records, } \\
\sigma_{\mathrm{a}_{1}}^{2}\left(\sigma_{\mathrm{a}_{2}}^{2}\right)= & \text { the additive genetic variance for Trait } \\
& \mathbf{1} \text { (Trait } 2), \\
\sigma_{\mathrm{a}_{1} \mathrm{a}_{2}}= & \text { the additive genetic covariance be- } \\
& \text { tween Traits } 1 \text { and } 2 \text {, and } \\
\sigma_{\mathrm{e}_{1}}^{2}\left(\sigma_{\mathrm{e}_{2}}^{2}\right)= & \text { the environmental variance for Trait } 1 \\
& \text { (Trait } 2) .
\end{aligned}
$$

The environmental covariance between traits is zero, which produces a diagonal matrix of residual variances with elements $\sigma_{\mathrm{e}_{1}}^{2}$ and $\sigma_{\mathrm{e}_{2}}^{2}$. The mixed-model equations (MME) are as follows: 


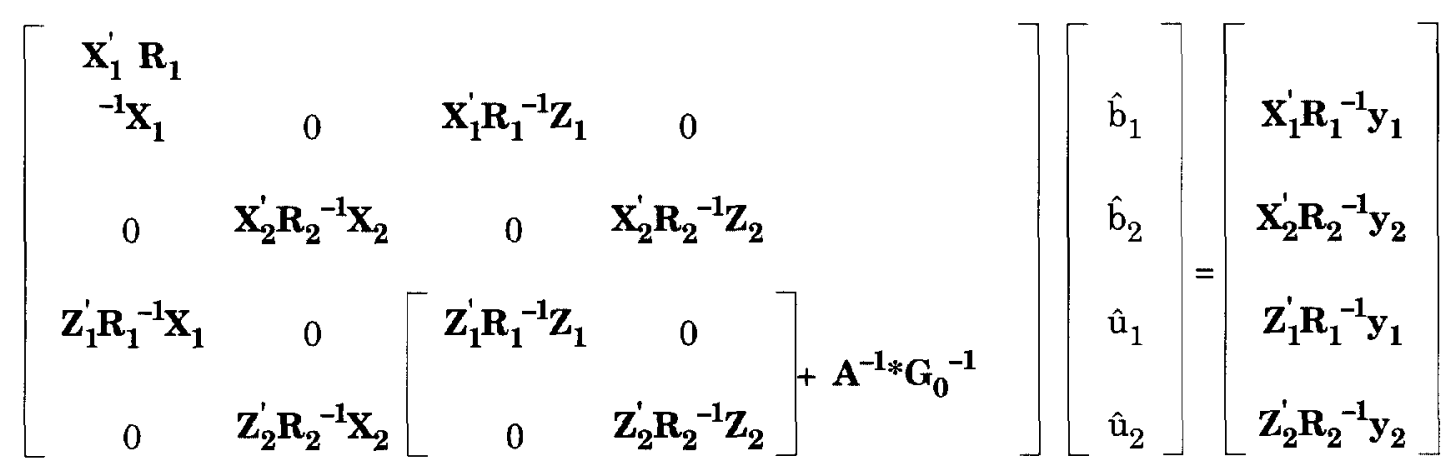

where $\mathbf{R}_{1}^{-1}=\mathbf{I}\left(1 / \sigma_{\mathrm{e}_{1}}^{2}\right), \mathbf{R}_{2}^{-1}=\mathbf{I}\left(\mathbf{1} / \sigma_{\mathbf{e}_{2}}^{2}\right), A^{-1}$ is the inverse of the numerator relationship matrix and $\mathbf{G}^{-1} \mathbf{0}$ is the inverse of the additive variance-covariance matrix.

\section{Derivative-Free Restricted Maximum}

Likelihood with a Sparse Matrix Solver

Boldman and Van Vleck (1991) described the incorporation of SPARSPAK (George et al., 1980), a sparse matrix package, into the original version of Meyer's derivative-free REML (DFREML) programs (1988a, 1988b, 1989). With SPARSPAK and the use of a Choleski factorization to obtain the log determinant of the coefficient matrix and the generalized residual sum of squares, the time needed to solve a system of equations was greatly reduced. Meyer (1991) discussed the extension of single-trait DFREML to multiple-trait DFREML with a specific bivariate example. Incorporating sparse matrix techniques for the bivariate model made these analyses computationally feasible. In the bivariable case the set of up-dated (co)variance components were chosen by the Simplex method each round (Nelder and Mead, 1965) to augment the MME in the next round

The convergence criterion was computed each round as the variance of the $\log$ likelihood values in the simplex until the variance was less than or equal to the convergence criterion $\left(1 \times 10^{-9}\right.$ or less). Several restarts for each analysis were performed to help ensure convergence was at the global maximum of the likelihood function (Press et al., 1986).

\section{Pelvic Measurement Analysis}

Records on 320-d pelvic width, height, and area for males and females were analyzed separately by breed group. Bivariate analyses were run on male and female measures for traits of the same name. Heritability estimates for each sex and trait were obtained along with genetic correlations between male and female pelvic widths, pelvic heights, and pelvic areas.

The model for each named pelvic trait used to estimate (co)variance components for each breed group included a covariate that adjusted pelvic measurements for julian birth day, fixed effects of dam age $(2,3,4, \geq 5)$ and year (1983 through 1990), and random effects for additive genetic effects of animal and uncorrelated residual effects. Three analyses were performed for each breed group. The paired traits were 320 -d pelvic width for males and females, as well as 320 -d pelvic height and 320-d pelvic area. The same pairs of traits were also analyzed after combining the 12 breed groups. In the combined analyses, the model was expanded to include the fixed effect of breed group. A minimum of two restarts of each analysis were conducted to help insure that convergence was to a global maximum.

\section{Male Pelvic Measures and Female 2-Year Old Calving Ease Analysis}

Pelvic measurements at $320 \mathrm{~d}$ for males and calving ease scores (actual and binary scale) of females calving as 2-yr-olds also were analyzed using a bivariate animal model. Models for 320-d pelvic width, height, and area of males were as described previously. The model for calving ease score of 2-yr-old females included a covariate for calf birth weight, fixed effect for year, and random effects for the additive genetic effect of animal and residual. Calving ease records were adjusted with a covariate of birth weight because birth weight contributes significantly to calving difficulty in 2-yr-old heifers. Calving ease was analyzed as either the actual or binary score. Calving ease scores were traits of the first-calving heifers and not of calves.

Six analyses of paired traits within each breed group were performed for pelvic width, height, or area at $320 \mathrm{~d}$ of males in combination with actual calving ease score or binary calving ease score of 2-yr-old heifers. In the combined analyses across all breed groups, breed group effects were included in the models for both male and female traits.

\section{Results and Discussion}

Numbers of bulls and heifers having 320-d pelvic measurements and 2-yr-old calving ease scores are in Table 1 for each breed group and all breed groups combined. The number of sires and dams for each breed group and number of animals in the relationship matrix for each trait and breed group are also in Table 1. The number of animals in the relationship matrix for all breed groups combined does not sum to 
Table 1. Number of males and females with 320-day pelvic measurements and 2-year-old females with calving ease records with number of sires, dams, and animals in relationship matrix by breed group

\begin{tabular}{|c|c|c|c|c|c|c|}
\hline Breed & $\begin{array}{c}\text { Male } \\
\text { 320-d pelvic } \\
\text { measurements }\end{array}$ & $\begin{array}{c}\text { Female } \\
\text { 320-d pelvic } \\
\text { measurements }\end{array}$ & $\begin{array}{c}\text { Female } \\
\text { calving } \\
\text { ease records }\end{array}$ & Sires & Dams & $\begin{array}{c}\text { Animals in } \\
\text { relationship } \\
\text { matrix }\end{array}$ \\
\hline Red Poll & 207 & 356 & 171 & 34 & 279 & 1,680 \\
\hline Braunvieh & 220 & 317 & 139 & 42 & 274 & 1,676 \\
\hline Hereford & 243 & 334 & 153 & 28 & 264 & 2,118 \\
\hline Angus & 309 & 400 & 177 & 42 & 390 & 2,744 \\
\hline Simmental & 225 & 298 & 139 & 37 & 251 & 1,909 \\
\hline Limousin & 254 & 350 & 150 & 37 & 282 & 1,882 \\
\hline Charolais & 229 & 368 & 170 & 37 & 292 & 1,825 \\
\hline Gelbvieh & 257 & 325 & 159 & 39 & 307 & 1,772 \\
\hline Pinzgauer & 220 & 313 & 140 & 31 & 255 & 1,498 \\
\hline MARC $I^{a}$ & 783 & 869 & 370 & 86 & 658 & 3,159 \\
\hline MARC II $^{\mathrm{a}}$ & 910 & 959 & 340 & 79 & 680 & 3,863 \\
\hline MARC III $^{\mathrm{a}}$ & 674 & 826 & 417 & 67 & 632 & 2,741 \\
\hline COMBINED $^{\mathrm{b}}$ & 4,531 & 5,715 & 2,525 & 559 & 4,564 & 26,071 \\
\hline
\end{tabular}

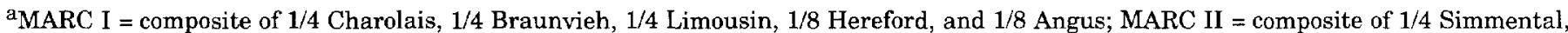
$1 / 4$ Gelbvieh, 1/4 Hereford, and 1/4 Angus; and MARC III = composite of $1 / 4$ Red Pool, $1 / 4$ Hereford, $1 / 4$ Pinzgauer, and $1 / 4$ Angus.

${ }^{b}$ COMBINED $=$ all breed groups combined.

the sum for the individual breed groups. Some dams of breed groups contributing to the composite populations produced purebred progeny and were granddams for progeny produced in composite populations. The number of bivariate animal model equations was twice the number of animals in the relationship matrix for each analysis plus the number of levels of fixed effects. For example for the Braunvieh breed group, there were 3,373 equations for analysis of male pelvic area and female calving ease $(1,676 \times 2+19$ fixed effect levels +2 covariates).

Means adjusted for Julian birth day and standard deviations by breed group and sex for 320-d pelvic width, height, and area are summarized in Table 2.
Hereford males had the smallest 320 -d male pelvic width, height, and area measurements, whereas Pinzgauer males had the largest 320-d male pelvic measurements. Hereford females exhibited the smallest 320-d female pelvic width, height, and area measurements, whereas Braunvieh females had the largest 320-d pelvic width. Charolais females had the largest pelvic height and area measurements of all breed groups.

Means and standard deviations for actual and binary scale calving ease score traits adjusted for calf birth weight by breed group are in Table 3. Binary scores for calving ease correspond to nearly no ( 0 ) or some (1) calving difficulty. Two-year-old Limousin

Table 2. Means ${ }^{\mathrm{a}}$ and standard deviations (SD) of pelvic measurements (cm) at 320 days for males and females by breed group

\begin{tabular}{|c|c|c|c|c|c|c|c|c|c|c|c|c|}
\hline \multirow[b]{2}{*}{ Breed } & \multicolumn{6}{|c|}{ Males } & \multicolumn{6}{|c|}{ Females } \\
\hline & $\begin{array}{c}\text { Pelvic } \\
\text { width, } \\
\mathrm{cm}\end{array}$ & SD & $\begin{array}{c}\text { Pelvic } \\
\text { height, } \\
\mathrm{cm}\end{array}$ & $\mathrm{SD}$ & $\begin{array}{c}\text { Pelvic } \\
\text { area, } \\
\mathrm{cm}^{2}\end{array}$ & SD & $\begin{array}{c}\text { Pelvic } \\
\text { width, } \\
\mathrm{cm}\end{array}$ & $\mathrm{SD}$ & $\begin{array}{c}\text { Pelvic } \\
\text { height, } \\
\mathrm{cm}\end{array}$ & $\mathrm{SD}$ & $\begin{array}{c}\text { Pelvic } \\
\text { area, } \\
\mathrm{cm}^{2}\end{array}$ & $\mathrm{SD}$ \\
\hline Red Poll & 11.15 & .96 & 12.42 & 1.20 & 139.33 & 21.54 & 11.05 & .80 & 12.64 & 1.01 & 140.11 & 17.93 \\
\hline Braunvieh & 11.73 & .94 & 12.78 & 1.02 & 151.29 & 21.14 & 11.80 & .79 & 13.21 & .86 & 156.25 & 17.80 \\
\hline Hereford & 10.38 & .94 & 11.78 & 1.16 & 122.65 & 20.06 & 10.24 & .83 & 11.72 & 1.02 & 120.80 & 17.59 \\
\hline Angus & 10.63 & 1.12 & 12.19 & 1.38 & 130.38 & 23.51 & 10.32 & .90 & 12.09 & 1.11 & 125.18 & 18.95 \\
\hline Simmental & 11.59 & 1.00 & 12.76 & 1.05 & 149.23 & 22.62 & 11.60 & .88 & 12.84 & .93 & 149.54 & 19.90 \\
\hline Limousin & 11.02 & 1.00 & 12.50 & 1.15 & 139.47 & 21.17 & 10.75 & .84 & 12.58 & .97 & 134.90 & 17.92 \\
\hline Charolais & 11.67 & .95 & 13.02 & 1.01 & 153.02 & 21.56 & 11.75 & .87 & 13.33 & .91 & 157.02 & 19.50 \\
\hline Gelbvieh & 11.56 & .97 & 12.64 & 1.15 & 147.15 & 23.19 & 11.56 & .79 & 12.98 & .94 & 150.68 & 19.00 \\
\hline Pinzgauer & 11.88 & 1.19 & 13.04 & 1.31 & 155.80 & 27.50 & 11.74 & .93 & 13.13 & 1.03 & 154.70 & 21.66 \\
\hline MARC I & 11.01 & .94 & 12.31 & .96 & 136.40 & 21.44 & 11.61 & 1.00 & 13.15 & 1.02 & 153.15 & 22.80 \\
\hline MARC II & 10.82 & .84 & 12.18 & .92 & 132.19 & 18.79 & 11.11 & .80 & 12.65 & .88 & 141.04 & 17.96 \\
\hline MARC III & 10.89 & .80 & 12.39 & .98 & 135.35 & 18.17 & 11.07 & .87 & 12.69 & 1.06 & 140.87 & 19.69 \\
\hline COMBINED & 11.03 & .97 & 12.36 & 1.09 & 137.24 & 21.83 & 11.25 & .92 & 12.78 & 1.04 & 144.60 & 20.81 \\
\hline
\end{tabular}

a Means adjusted to a common julian birth day. 
Table 3. Means ${ }^{\mathrm{a}}$ and standard deviations (SD) for calving ease scores of 2-year-old heifers by breed group

\begin{tabular}{lcccc}
\hline \hline Breed & CE $1^{\mathrm{b}}$ & SD & CE 2 & SD \\
\hline Red Poll & 2.67 & 1.48 & .58 & .49 \\
Braunvieh & 3.02 & 1.58 & .62 & .47 \\
Hereford & 2.47 & 1.54 & .47 & .50 \\
Angus & 2.18 & 1.48 & .40 & .49 \\
Simmental & 2.42 & 1.54 & .47 & .50 \\
Limousin & 1.82 & 1.39 & .27 & .45 \\
Charolais & 1.98 & 1.38 & .34 & .46 \\
Gelbvieh & 2.76 & 1.69 & .53 & .50 \\
Pinzgauer & 3.06 & 1.61 & .64 & .47 \\
MARC I & 2.74 & 1.68 & .50 & .53 \\
MARC II & 2.57 & 1.56 & .51 & .48 \\
MARC III & 2.35 & 1.54 & .49 & .44 \\
COMBINED & 2.50 & 1.56 & .48 & .49 \\
\hline
\end{tabular}

${ }^{\mathrm{a}}$ Means adjusted for birth weight of calf.

${ }^{\mathrm{b}} \mathrm{CE} 1$ are calving ease scores using the following scale: 1 = no difficulty, 2 = little difficulty by hand, $3=$ little difficulty with calf jack, 4 = slight difficulty with calf jack, $5=$ moderate difficulty with calf jack, and 6 = major difficulty with calf jack.

${ }^{c} \mathrm{CE} 2$ are scores expressed on a binary scale with $0=$ scores 1 and 2 and $1=$ scores $3,4,5,6$ from $b$.

females had the least amount of calving difficulty, whereas Pinzgauer heifers exhibited the most calving difficulty.

Efforts were made to ensure that derivative-free REML analyses of pelvic traits converged to a global maximum of the likelihood function by restarting each analysis several times. However, many of the breed groups had few animals with records and apparently little additive genetic variation. The genetic correlation is estimated only through relationships between males and females. These factors may have caused many of the analyses of individual breeds to converge to a genetic correlation of 1.0 between male and female pelvic traits. In some analyses finding the global maximum was difficult. The analysis with all breed groups combined converged to the same likelihood value after each restart.

Estimates of additive genetic (co)variances and environmental variances for pelvic measurements by breed group are in Table 4. Estimates of additive genetic (co)variances ranged widely across breed groups for all pelvic traits. Generally, additive genetic variances were larger in females than in males. However, variance estimates were similar for males and females for all pelvic traits when breeds were combined and analyzed together. The combined analy-

Table 4. (Co)variance ${ }^{a}$ estimates for pelvic measurements at 320 days for males and females using a bivariate animal model and restricted maximum likelihood

\begin{tabular}{|c|c|c|c|c|c|c|c|c|c|c|c|c|c|c|c|}
\hline \multirow[b]{2}{*}{ Breed } & \multicolumn{5}{|c|}{ Pelvic width, $\mathrm{cm}^{2}$} & \multicolumn{5}{|c|}{ Pelvic height, $\mathrm{cm}^{2}$} & \multicolumn{5}{|c|}{ Pelvic area, $\mathrm{cm}^{4}$} \\
\hline & $\sigma_{\mathrm{a}_{\mathrm{M}}}^{2}$ & $\sigma_{\mathrm{a}_{\mathrm{M}^{\mathrm{a}} \mathrm{F}}}$ & $\sigma_{\mathrm{a}_{\mathbf{F}}}^{2}$ & $\sigma_{\mathrm{e}_{\mathrm{M}}}^{2}$ & $\sigma_{\mathrm{e}_{\mathrm{F}}}^{2}$ & $\sigma_{\mathrm{a}_{\mathrm{M}}}^{2}$ & $\sigma_{\mathrm{a}_{M^{\mathrm{a}} \mathbf{F}}}$ & $\sigma_{\mathrm{a}_{\mathrm{F}}}^{2}$ & $\sigma_{\mathbf{e}_{\mathrm{M}}}^{2}$ & $\sigma_{\mathbf{e}_{\mathrm{F}}}^{2}$ & $\sigma_{\mathrm{a}_{\mathrm{M}}}^{2}$ & $\sigma_{\mathrm{a}_{\mathrm{M}^{\mathrm{a}} \mathrm{F}}}$ & $\sigma_{\mathrm{a}_{\mathrm{F}}}^{2}$ & $\sigma_{\mathbf{e}_{\mathrm{M}}}^{2}$ & $\sigma_{\mathrm{e}_{\mathrm{F}}}^{2}$ \\
\hline Red Poll & .03 & .08 & .22 & .30 & .31 & .00 & .00 & .06 & .48 & .78 & 1.36 & 9.75 & 70.21 & 152,36 & 201.97 \\
\hline Braunvieh & .03 & .06 & .12 & .26 & .51 & .00 & .00 & .01 & .48 & .63 & 3.46 & 8.67 & 21.76 & 155.43 & 284.29 \\
\hline Hereford & .17 & .15 & .13 & .20 & .49 & .26 & .22 & .18 & .36 & .71 & 66.43 & 70.88 & 75.63 & 103.79 & 201.51 \\
\hline Angus & .04 & .04 & .09 & .42 & .41 & .04 & .02 & .08 & .49 & .83 & 21.01 & 9.22 & 45.57 & 160.26 & 197.54 \\
\hline Simmental & .13 & .14 & .15 & .30 & .48 & .08 & .09 & .11 & .44 & .57 & 47.69 & 57.97 & 70.47 & 168.23 & 258.78 \\
\hline Limousin & .15 & .03 & .05 & .36 & .47 & .25 & -.10 & .28 & .19 & .61 & 96.66 & 2.82 & 63.62 & 96.62 & 204.58 \\
\hline Charolais & .31 & .20 & .15 & .25 & .44 & .11 & .04 & .13 & .49 & .52 & 124.50 & 79.30 & 80.11 & 143.67 & 231.92 \\
\hline Gelbvieh & .07 & .00 & .03 & .28 & .50 & .07 & .04 & .12 & .49 & .51 & 29.28 & 13.16 & 25.61 & 169.65 & 257.36 \\
\hline Pinzgauer & .21 & .25 & .29 & .36 & .37 & .33 & .30 & .29 & .62 & .37 & 127.31 & 136.48 & 146.32 & 205.06 & 185.55 \\
\hline MARC I & .04 & .10 & .27 & .73 & .43 & .08 & .09 & .11 & .83 & .51 & 26.05 & 49.43 & 93.80 & 393.11 & 240.31 \\
\hline MARC II & .10 & .12 & .18 & .42 & .41 & .05 & .09 & .17 & .61 & .50 & 31.09 & 50.72 & 82.77 & 230.88 & 209.34 \\
\hline MARC III & .08 & .10 & .16 & .37 & .35 & .16 & .06 & .12 & .53 & .60 & 46.00 & 35.54 & 63.76 & 187.63 & 193.30 \\
\hline COMBINED & .16 & .11 & .17 & .46 & .44 & .17 & .07 & .14 & .66 & .59 & 78.72 & 46.79 & 74.85 & 244.91 & 226.08 \\
\hline
\end{tabular}

$\mathrm{a}_{\sigma_{\mathrm{a}_{M}}^{2}}^{2}=$ additive genetic variance for trait on males; $\sigma_{\mathrm{a}_{\mathrm{F}}}^{2}$ additive genetic variance for trait on females; $\sigma_{\mathrm{a}_{\mathrm{M}} \mathrm{a}_{\mathrm{F}}}=$ additive genetic covariance between trait on males and females; $\sigma_{\mathrm{e}_{\mathrm{M}}}^{2}=$ environmental variance for trait on males; $\sigma_{\mathrm{e}_{\mathrm{F}}}^{2}=$ environmental variance for trait on females. 
Table 5. Estimates of heritabilities and genetic correlations ${ }^{a}$ for pelvic traits at 320 days for males and females from a bivariate animal model and restricted maximum likelihood

\begin{tabular}{|c|c|c|c|c|c|c|c|c|c|}
\hline \multirow[b]{3}{*}{ Breed } & \multicolumn{9}{|c|}{ Trait } \\
\hline & \multicolumn{3}{|c|}{ Pelvic width } & \multicolumn{3}{|c|}{ Pelvic height } & \multicolumn{3}{|c|}{ Pelvic area } \\
\hline & $\mathrm{h}_{\mathrm{M}}^{2}$ & $\mathrm{r}_{\mathrm{MF}}$ & $\mathrm{h}_{\mathrm{F}}^{2}$ & $\mathrm{~h}_{\mathrm{M}}^{2}$ & $\mathrm{r}_{\mathrm{MF}}$ & $\mathrm{h}_{\mathrm{F}}^{2}$ & $h_{M}^{2}$ & $\mathrm{r}_{\mathrm{MF}}$ & $h_{F}^{2}$ \\
\hline Red Poll & .10 & 1.00 & .41 & .00 & 1.00 & .07 & .01 & 1.00 & .26 \\
\hline Braunvieh & .10 & 1.00 & .19 & .00 & 1.00 & .01 & .02 & 1.00 & .07 \\
\hline Hereford & .46 & 1.00 & .21 & .42 & 1.00 & .20 & .39 & 1.00 & .27 \\
\hline Angus & .09 & .58 & .18 & .08 & .20 & .09 & .12 & .30 & .19 \\
\hline Simmental & .31 & 1.00 & .25 & .16 & 1.00 & .16 & .22 & 1.00 & .21 \\
\hline Limousin & .29 & .41 & .09 & .57 & -.40 & .31 & .50 & .04 & .24 \\
\hline Charolais & .56 & .90 & .26 & .18 & .37 & .20 & .47 & .79 & .26 \\
\hline Gelbvieh & .19 & .09 & .06 & .12 & .43 & .20 & .15 & .48 & .09 \\
\hline Pinzgauer & .37 & 1.00 & .44 & .35 & .97 & .44 & .39 & 1.00 & .44 \\
\hline MARC I & .05 & 1.00 & .38 & .08 & .95 & .17 & .06 & 1.00 & .28 \\
\hline MARC II & .19 & .91 & .30 & .07 & 1.00 & .25 & .12 & 1.00 & .28 \\
\hline MARC III & .18 & .90 & .32 & .23 & .42 & .17 & .20 & .66 & .25 \\
\hline COMBINED & .26 & .68 & .28 & .20 & .48 & .19 & .24 & .61 & .25 \\
\hline
\end{tabular}

${ }^{a} h_{M}^{2}=$ heritability estimate for male trait; $h_{F}^{2}=$ heritability estimate for female trait; $r_{M F}=$ genetic correlation between male and female trait.

sis represents a weighted average of all breed groups; years connected the breed groups together. Benyshek and Little (1982) reported additive genetic variances for pelvic width, pelvic height, and pelvic area of 365 -d Simmental females to be $.32 \mathrm{~cm}^{2}, .28 \mathrm{~cm}^{2}$, and $153.04 \mathrm{~cm}^{4}$, respectively, using a sire model. Naazie et al. (1991), also for a sire model, reported additive genetic variances for pelvic width, pelvic height, and pelvic area of $.75 \mathrm{~cm}^{2}, .36 \mathrm{~cm}^{2}$, and $490.0 \mathrm{~cm}^{4}$, respectively, for 2-yr-old postpartum females of a synthetic beef breed. These literature values are larger than the additive genetic variances found in the analyses reported here for both males or females.

Table 5 lists heritability estimates for each male and female $320-\mathrm{d}$ pelvic trait along with the additive genetic correlations between measures on males and females. Most heritability estimates of male and female 320 -d pelvic width (.05 to .46$)$, height (.00 to $.57)$, and area (.01 to .47) were low to moderate in size. When breed groups were combined, heritability estimates were similar for both males and females and moderate in size. Most previous research has found higher heritability estimates for these traits. Heritability estimates in the literature ranged from .49 to .99 for pelvic width, .43 to 1.01 for pelvic height, and .46 to .97 for pelvic area (Benyshek and Little, 1982; Morrison et al., 1986; Nelson et al., 1986; Green et al., 1988; Naazie et al., 1991). However, Neville and coworkers (1978) using four breeds of cattle at two locations reported heritability estimates of .18 and .22 for pelvic width, .10 and .38 for pelvic height, and .04 and .24 for pelvic area. Holzer and Schlote (1984) obtained heritability estimates of $.42, .29$, and .36 for pelvic width, height, and area, respectively, measured 2 wk postpartum on 1,400 Simmental first-calf heifers.
Estimates from the latter two studies are in close agreement with those obtained in this study.

Genetic correlations between 320- $d$ male and female pelvic widths were positive and large with the exception of the estimate for the Gelbvieh breed group (.09). Many of the estimates approached 1.00. This trend was also evident for genetic correlations between pelvic height or pelvic area of males and females. A negative genetic correlation for the Limousin breed was found for pelvic height $(-.40)$. This negative correlation may be due to sampling. When all breed groups were combined, estimates of genetic correlations were $.68, .48$, and .61 between males and females for pelvic width, height, and area, respectively. The genetic correlation of .61 between 320 -d pelvic area of males and females agrees with Green et al. (1986), who reported a genetic correlation of .60 . These estimates from combined data suggest male and female pelvic traits are largely under the same genetic control but that these named traits should be considered to be correlated traits rather than the same trait in males and females.

A question is what correlated genetic response would be expected in female calving ease from selection of bulls on pelvic measurements. The expected genetic response in daughters for a particular trait is as follows:

$$
\Delta \mathrm{G}_{2}=\mathrm{b}_{\mathrm{G}_{2}} \cdot \mathrm{P}_{1} \cdot \mathrm{SD}
$$

where $b_{G_{2}} \cdot P_{1}$ is the regression of daughter genotype for Trait 2 on the phenotype of the sire for Trait 1 and $\mathrm{SD}$ is the phenotypic selection differential of sire for Trait 1. The selection differential of a sire can be expressed as $\mathrm{X}_{1}-\overline{\mathrm{X}}_{1}$, a sire's measurement minus the average of all sires' measurements. 
The regression,

$$
\begin{aligned}
\mathrm{b}_{\mathrm{G}_{2}, \mathrm{P}_{1}}= & \frac{\operatorname{CoV}\left(\mathrm{G}_{2}, \mathrm{P}_{1}\right)}{\sigma_{\mathrm{P}_{1}^{2}}} \\
= & \frac{.5 \mathrm{r}_{12} \mathrm{~h}_{1} \mathrm{~h}_{2} \sigma_{\mathrm{P}_{2}}}{\sigma_{\mathrm{P}_{1}}}
\end{aligned}
$$

where $r_{12}$ is the genetic correlation between Traits 1 and $2, \sigma_{\mathrm{P}_{2}}$ is the phenotypic standard deviation for Trait 2, and $h_{1}$ and $h_{2}$ are the square roots of heritabilities for Traits 1 and 2 , respectively. Thus, expected genetic response in daughters for a trait given that their sire is selected on a different trait measured on the sire is as follows:

$$
\Delta \mathrm{G}_{2}=\frac{\left(.5 \mathrm{r}_{12} \mathrm{~h}_{1} \mathrm{~h}_{2}{ } \mathrm{P}_{2}\right)}{\sigma_{\mathrm{P}_{1}}}\left(\mathrm{X}_{1}-\overline{\mathrm{X}}_{1}\right) .
$$

For a sire one standard deviation above the mean for pelvic width $(\sigma=.79 \mathrm{~cm})$, pelvic height $(\sigma=.91 \mathrm{~cm})$, or pelvic area $\left(\sigma=17.99 \mathrm{~cm}^{2}\right)$, the expected genetic response in his average daughter's pelvic width, pelvic height, and pelvic area is an increase of $.07 \mathrm{~cm}, .04$ $\mathrm{cm}$, and $1.30 \mathrm{~cm}^{2}$, respectively. Thus, if sires are selected based on increased pelvic measurements, a small positive genetic change for each trait in female offspring will be expected. Brinks (1987) and Green et al. (1988) concur that pelvic size will increase in females when produced by sires with larger pelvic measurements. However, these predicted increases are rather small especially if pelvic area is not the primary trait of interest in bull selection.

However, if pelvic size in daughters increases, another concern is whether the mature size of the daughters will increase. Bellows et al. (1971) and Laster (1974) suggest that increasing pelvic area will increase mature size and weight in the female. Benyshek and Little (1982) reported a genetic correlation of .65 between $365-\mathrm{d}$ pelvic area and weight but only a small environmental correlation. Morrison et al. (1986) reported a small phenotypic correlation between pelvic area and mature cow weight.

Table 6 contains estimates of additive genetic (co)variances and environmental variances for pelvic traits of males and actual calving ease scores of females. Estimates for pelvic traits of males and binary calving ease scores are in Table 7 . As in the previous analyses involving male pelvic traits, estimates of additive genetic variances varied by breed. Co(variance) estimates for the three male pelvic traits were similar within breed group for each of the three analyses with calving ease.

Estimates of additive genetic variances for actual calving ease were also variable across breed groups, but similar to the analyses with the three pelvic traits of males. The same pattern was also evident for analyses of calving ease on the binary scale. Naazie et al. (1991) reported additive genetic variance for actual calving ease scores to be .49 and for binary scale scores to be .05 for heifers of three synthetic beef breeds. For Angus data, Cubas et al. (1991) reported

\begin{tabular}{|c|c|c|c|c|c|c|c|c|c|c|c|c|c|c|c|}
\hline \multirow[b]{3}{*}{ Breed } & \multicolumn{15}{|c|}{ Trait $^{\mathrm{a}}$} \\
\hline & \multicolumn{5}{|c|}{ Pelvic width, CE 1} & \multicolumn{5}{|c|}{ Pelvic height, CE 1} & \multicolumn{5}{|c|}{ Pelvic area, CE 1} \\
\hline & $\sigma_{\mathrm{a}_{\mathrm{M}}}^{2}$ & $\sigma_{\mathrm{a}_{\mathbf{M}^{\mathrm{a}} \mathbf{F}}}$ & $\sigma_{\mathrm{a}_{\mathrm{F}}}^{2}$ & $\sigma_{\mathrm{e}_{\mathrm{M}}}^{2}$ & $\sigma_{\mathrm{e}_{\mathrm{F}}}^{2}$ & $\sigma_{\mathrm{a}_{\mathrm{M}}}^{2}$ & $\sigma_{\mathrm{a}_{\mathrm{M}}} \mathrm{a}_{\mathrm{F}}$ & $\sigma_{\mathrm{a}_{\mathrm{F}}}^{2}$ & $\sigma_{\mathrm{e}_{\mathrm{M}}}^{2}$ & $\sigma_{\mathrm{e}_{\mathrm{F}}}^{2}$ & $\sigma_{\mathrm{a}_{\mathrm{M}}}^{2}$ & $\sigma_{\mathrm{a}_{\mathrm{M}} \mathrm{a}_{\mathrm{F}}}$ & $\sigma_{\mathrm{a}_{\mathrm{F}}}^{2}$ & $\sigma_{\mathrm{e}_{\mathrm{M}}}^{2}$ & $\sigma_{\mathrm{e}_{\mathrm{F}}}^{2}$ \\
\hline Red Poll & .00 & -.03 & .35 & .32 & 1.97 & .00 & -.00 & .27 & .48 & 2.03 & .00 & -.00 & .27 & 153.35 & 2.03 \\
\hline Braunvieh & .02 & -.12 & 1.12 & .27 & 1.50 & .01 & -.12 & 1.19 & .48 & 1.44 & 4.93 & -2.43 & 1.19 & 155.04 & 1.42 \\
\hline Hereford & .09 & -.30 & 1.03 & .26 & 1.52 & .14 & -.25 & .98 & .45 & 1.57 & 29.77 & -5.33 & .95 & 131.71 & 1.58 \\
\hline Angus & .05 & .07 & .10 & .42 & 2.11 & .04 & .02 & .13 & .49 & 2.09 & 21.23 & .99 & .11 & 160.05 & 2.10 \\
\hline Simmental & .11 & .06 & .33 & .32 & 2.08 & .06 & .17 & .51 & .46 & 1.94 & 35.68 & 2.63 & .44 & 178.45 & 2.00 \\
\hline Limousin & .12 & -.02 & .16 & .39 & 1.78 & .23 & -.04 & .14 & .20 & 1.79 & 95.31 & -1.05 & .16 & 98.17 & 1.78 \\
\hline Charolais & .19 & .02 & 1.00 & .34 & 1.06 & .09 & -.13 & 1.01 & .50 & 1.05 & 91.04 & -.81 & 1.02 & 167.32 & 1.05 \\
\hline Gelbvieh & .06 & -.07 & .16 & .28 & 2.72 & .06 & .00 & .19 & .50 & 2.68 & 28.27 & -.78 & .18 & 170.51 & 2.70 \\
\hline Pinzgauer & .17 & -.02 & .11 & .39 & 2.51 & .35 & -.02 & .10 & .60 & 2.52 & 124.40 & -.81 & .11 & 210.29 & 2.52 \\
\hline MARC I & .04 & .11 & .68 & .73 & 2.21 & .07 & .08 & .68 & .83 & 2.20 & 24.22 & 2.30 & .68 & 394.64 & 2.20 \\
\hline MARC II & .11 & -.06 & .04 & .41 & 2.40 & .03 & -.03 & .02 & .63 & 2.42 & 36.40 & -.14 & .00 & 227.14 & 2.44 \\
\hline MARC III & .07 & -.03 & .06 & .37 & 2.39 & .16 & -.03 & .06 & .53 & 2.33 & 42.70 & -.69 & .05 & 190.85 & 2.33 \\
\hline COMBINED & .15 & -.06 & .27 & .46 & 2.23 & .16 & -.04 & .26 & .66 & 2.23 & 75.58 & -1.13 & .26 & 247.35 & 2.23 \\
\hline
\end{tabular}

Table 6. (Co)variance estimates ${ }^{\mathbf{a}}$ for pelvic measurements at 320 days of males and actual calving ease (CE 1) scores of 2-year-old females using a bivariate animal model and restricted maximum likelihood

a320-Day male pelvic width and pelvic height variance units are squared centimeters; pelvic area is quadrupled centimeters; 2-yr-old calving ease is units squared; additive genetic covariance is centimeter $\times$ unit or squared centimeters $\times$ units. $\sigma_{\mathrm{a}_{\mathrm{M}}}^{2}=$ additive genetic variance for trait on males; $\sigma_{\mathrm{a}_{\mathrm{F}}}^{2}$ additive genetic variance for trait on females; $\sigma_{\mathrm{a}_{\mathrm{M}_{\mathrm{F}}}}=$ additive genetic covariance between trait on males and females; $\sigma_{\mathrm{e}_{\mathrm{M}}}^{2}=$ environmental variance for trait on males; $\sigma_{\mathrm{e}_{\mathrm{F}}}^{2}=$ environmental variance for trait on females. 
Table 7. (Colvariance estimates ${ }^{\mathrm{a}}$ for pelvic measurements at 320 days of males and binary calving ease (CE 2) scores of 2-year-old females using a bivariate animal model and restricted maximum likelihood

\begin{tabular}{|c|c|c|c|c|c|c|c|c|c|c|c|c|c|c|c|}
\hline \multirow[b]{3}{*}{ Breed } & \multicolumn{15}{|c|}{ Trait $^{\mathrm{a}}$} \\
\hline & \multicolumn{5}{|c|}{ Pelvic width, CE 2} & \multicolumn{5}{|c|}{ Pelvic height, CE 2} & \multicolumn{5}{|c|}{ Pelvic area, CE 2} \\
\hline & $\sigma_{\mathrm{a}_{\mathrm{M}}}^{2}$ & $\sigma_{\mathrm{a}_{\mathrm{M}} \mathrm{a}_{\mathrm{F}}}$ & $\sigma_{\mathrm{a}_{\mathrm{F}}}^{2}$ & $\sigma_{\mathrm{e}_{\mathrm{M}}}^{2}$ & $\sigma_{\mathrm{e}_{\mathrm{F}}}^{2}$ & $\sigma_{\mathrm{a}_{\mathrm{M}}}^{2}$ & $\sigma_{\mathrm{a}_{\mathrm{M}^{\mathrm{a}} \mathrm{F}}}$ & $\sigma_{\mathbf{a}_{\mathbf{F}}}^{2}$ & $\sigma_{\mathrm{e}_{\mathrm{M}}}^{2}$ & $\sigma_{\mathrm{e}_{F}}^{2}$ & $\sigma_{\mathrm{a}_{\mathrm{M}}}^{2}$ & $\sigma_{\mathrm{a}_{\mathrm{M}} \mathrm{a}_{\mathrm{F}}}$ & $\sigma_{\mathrm{a}_{\mathrm{F}}}^{2}$ & $\sigma_{\mathrm{e}_{\mathrm{M}}}^{2}$ & $\sigma_{\mathrm{e}_{\mathrm{F}}}^{2}$ \\
\hline Red Poll & .00 & -.00 & .00 & .32 & .25 & .00 & -.00 & .00 & .48 & .24 & .02 & .00 & .00 & 153.45 & .25 \\
\hline Braunvieh & .02 & -.03 & .04 & .26 & .19 & .01 & -.02 & .04 & .47 & .18 & .63 & -.03 & .03 & 160.50 & .22 \\
\hline Hereford & .11 & -.07 & .04 & .24 & .21 & .15 & -.07 & .04 & .44 & .21 & 37.33 & -1.33 & .05 & 125.54 & .21 \\
\hline Angus & .05 & .01 & .00 & .47 & .24 & .04 & .01 & .00 & .49 & .24 & 24.06 & -.08 & .00 & 157.76 & .24 \\
\hline Simmental & .11 & .01 & .00 & .32 & .25 & .05 & .02 & .01 & .47 & .24 & 35.98 & .37 & .00 & 176.73 & .25 \\
\hline Limousin & .12 & -.02 & .05 & .38 & .16 & .23 & -.02 & .04 & .20 & .16 & 94.97 & -.52 & .05 & 98.39 & .16 \\
\hline Charolais & .19 & .01 & .08 & .34 & .14 & .09 & -.05 & .08 & .50 & .14 & 90.66 & -.29 & .08 & 167.37 & .14 \\
\hline Gelbvieh & .07 & .00 & .04 & .28 & .22 & .06 & .02 & .04 & .50 & .21 & 30.43 & .27 & .04 & 168.65 & .21 \\
\hline Pinzgauer & .17 & .00 & .03 & .39 & .19 & .37 & .02 & .04 & .60 & .19 & 124.23 & .11 & .03 & 210.40 & .19 \\
\hline MARC I & .03 & .03 & .05 & .73 & .20 & .07 & .03 & .05 & .83 & .20 & 22.97 & .71 & .05 & 395.59 & .20 \\
\hline MARC II & .11 & -.02 & .00 & .41 & .23 & .03 & -.00 & .00 & .63 & .23 & 35.05 & -.10 & .00 & 227.49 & .23 \\
\hline MARC III & .07 & -.01 & .00 & .37 & .24 & .16 & -.02 & .00 & .53 & .24 & 42.49 & -.33 & .00 & 190.84 & .24 \\
\hline COMBINED & .15 & -.02 & .02 & .46 & .22 & .16 & -.01 & .02 & .66 & .22 & 75.73 & -.27 & .02 & 247.21 & .22 \\
\hline
\end{tabular}

a320-Day male pelvic width and pelvic height variance units are squared centimeters; pelvic area is quadrupled centimeters; 2 -yr-old calving ease is units squared; additive genetic covariance is centimeter $\times$ unit or squared centimeters $\times$ units. $\sigma_{a_{M}}^{2}=$ additive genetic variance for trait on males; $\sigma_{\mathrm{a}_{\mathbf{F}}}^{2}$ additive genetic variance for trait on females; $\sigma_{\mathrm{a}_{M}{ }_{\mathbf{F}}}=$ additive genetic covariance between trait on males and females; $\sigma_{\mathrm{e}_{\mathrm{M}}}^{2}=$ environmental variance for trait on males; $\sigma_{\mathrm{e}_{\mathrm{F}}}^{2}=$ environmental variance for trait on females.

genetic variance to be .11 for actual calving ease scores. Both sets of estimates agree with the combined analyses reported here.

Table 8 provides estimates of heritability and genetic correlations for the analyses between paired pelvic measurements of males and calving ease scores of heifers. Heritability estimates of actual calving ease or binary scale calving ease were similar across breed groups and for the combined analyses. Heritability estimates of actual calving ease found by Cubas et al. (1991) and Naazie et al. (1991) of .27 and .41 are larger than the estimates obtained for the combined analyses. Naazie et al. (1991) also reported an heritability estimate of .12 for calving ease on a binary scale, which is similar to estimates found in these analyses.

Table 8. Estimates of heritabilities and genetic correlations $s^{a}$ between pelvic measurements of males and calving ease actual (CE 1) and binary (CE 2) scores of 2-year-old females

\begin{tabular}{|c|c|c|c|c|c|c|c|c|c|c|c|c|c|c|c|c|c|c|}
\hline \multirow[b]{3}{*}{ Breed } & \multicolumn{18}{|c|}{ Trait } \\
\hline & \multicolumn{3}{|c|}{$\begin{array}{l}\text { Pelvic width, } \\
\text { CE } 1\end{array}$} & \multicolumn{3}{|c|}{$\begin{array}{l}\text { Pelvic width, } \\
\text { CE } 2\end{array}$} & \multicolumn{3}{|c|}{$\begin{array}{l}\text { Pelvic height, } \\
\text { CE } 1\end{array}$} & \multicolumn{3}{|c|}{$\begin{array}{c}\text { Pelvic height, } \\
\text { CE } 2\end{array}$} & \multicolumn{3}{|c|}{$\begin{array}{l}\text { Pelvic area, } \\
\text { CE } 1\end{array}$} & \multicolumn{3}{|c|}{$\begin{array}{l}\text { Pelvic area, } \\
\text { CE } 2\end{array}$} \\
\hline & $\mathrm{h}_{\mathrm{M}}^{2}$ & $\mathrm{r}_{\mathrm{MF}}$ & $h_{\mathrm{F}}^{2}$ & $\mathrm{~h}_{\mathrm{M}}^{2}$ & $\mathrm{r}_{\mathrm{MF}}$ & $\mathrm{h}_{\mathrm{F}}^{2}$ & $\mathrm{~h}_{\mathbf{M}}^{2}$ & $\mathrm{r}_{\mathrm{MF}}$ & $\mathrm{h}_{\mathrm{F}}^{2}$ & $\mathrm{~h}_{\mathrm{M}}^{2}$ & $\mathbf{r}_{\mathrm{MF}}$ & $\mathrm{h}_{\mathrm{F}}^{2}$ & $\mathbf{h}_{\mathrm{M}}^{2}$ & $\mathrm{r}_{\mathrm{MF}}$ & $\mathrm{h}_{\mathrm{F}}^{2}$ & $\mathrm{~h}_{\mathrm{M}}^{2}$ & $\mathrm{r}_{\mathrm{MF}}$ & $\mathrm{h}_{\mathrm{F}}^{2}$ \\
\hline Red Poll & .01 & -1.00 & .15 & .00 & -1.00 & .00 & .00 & -.05 & .12 & .00 & -.99 & .00 & .00 & -1.00 & .12 & .00 & 1.00 & .00 \\
\hline Braunvieh & .05 & -.95 & .43 & .07 & -1.00 & .17 & .02 & -1.00 & .45 & .03 & -1.00 & .19 & .03 & -1.00 & .46 & .00 & -1.00 & .12 \\
\hline Hereford & .26 & -1.00 & .40 & .32 & -1.00 & .17 & .24 & -.66 & .38 & .26 & -.85 & .17 & .18 & -1.00 & .38 & .23 & -1.00 & .18 \\
\hline Angus & .10 & 1.00 & .05 & .11 & 1.00 & .00 & .07 & .34 & .06 & .08 & 1.00 & .01 & .12 & .64 & .05 & .13 & -1.00 & .00 \\
\hline Simmental & .26 & .29 & .14 & .26 & 1.00 & .00 & .12 & 1.00 & .21 & .09 & .99 & .03 & .17 & .66 & .18 & .17 & 1.00 & .02 \\
\hline Limousin & .23 & -.17 & .08 & .24 & -.26 & .24 & .55 & -.26 & .07 & .54 & -.20 & .21 & .49 & -.27 & .08 & .49 & -.25 & .22 \\
\hline Charolais & .36 & .04 & .48 & .36 & .06 & .37 & .16 & -.43 & .49 & .16 & -.53 & .36 & .35 & -.08 & .49 & .35 & -.10 & .37 \\
\hline Gelbvieh & .17 & -.73 & .05 & .19 & .08 & .14 & .11 & .04 & .07 & .11 & .44 & .15 & .14 & -.35 & .06 & .15 & .25 & .15 \\
\hline Pinzgauer & .30 & -.15 & .04 & .30 & .02 & .15 & .37 & -.12 & .04 & .38 & .19 & .16 & .37 & -.22 & .04 & .37 & .05 & .15 \\
\hline MARC I & .05 & .68 & .23 & .04 & .87 & .18 & .08 & .37 & .24 & .08 & .46 & .19 & .06 & .57 & .24 & .05 & .68 & .19 \\
\hline MARC II & .21 & -1.00 & .01 & .21 & -1.00 & .02 & .05 & -1.00 & .01 & .05 & -.97 & .00 & .14 & -1.00 & .00 & .13 & -1.00 & .01 \\
\hline MARC III & .16 & -.48 & .02 & .16 & -1.00 & .01 & .23 & -.27 & .03 & .23 & -.90 & .01 & .18 & -.45 & .02 & .18 & -1.00 & .01 \\
\hline COMBINED & .25 & -.29 & .11 & .25 & -.29 & .09 & .20 & -.22 & .11 & .20 & -.14 & .09 & .23 & -.25 & .11 & .23 & -.22 & .09 \\
\hline
\end{tabular}

${ }^{a} h_{M}^{2}=$ heritability estimate for male trait; $h_{F}^{2}=$ heritability estimate for female trait; $r_{M F}=$ genetic correlation between male and female trait. 
Estimates of additive genetic correlation between male pelvic traits and actual female calving ease scores were variable, but generally negative. Again, several correlations converged to 1.00 or -1.00 , which are not realistically possible. Generally, estimates of 1.00 or -1.00 occurred when one of the estimates of additive genetic variance was close to zero. However, when all breed groups were combined, moderate negative correlations were found between pelvic width, height, and area of males and actual calving ease scores of 2 -yr-old heifers $(-.29,-.22,-.25)$. This result suggests that as pelvic measurements increase in male contemporaries, a small to moderate decrease in calving difficulty would be expected in females. These correlations represent a maximum possible change especially if female pelvic size is positively correlated with calf birth weight or other growth traits in general. Naazie et al. (1991) for a sire model reported a genetic correlation between pelvic area measured postpartum and calving ease score of -.21 in beef heifers.

The same patterns were observed for estimates of genetic correlation in analyses of male pelvic traits paired with calving ease on the binary scale. Again, several genetic correlation estimates converged to 1.00 or -1.00 . However, when all data were combined, moderate negative genetic correlations were found between male pelvic traits and binary scores for calving ease $(-.29,-.14,-.22)$. These results indicate a decrease in the incidence of female calving difficulty as pelvic measurements increase in male relatives. Naazie et al. (1991), however, estimated the genetic correlation between pelvic area and binary calving ease to be .08 , using data on heifers of synthetic breeds.

An important question to answer is whether a sire's pelvic measurements will predict the subsequent calving ease of his daughters (i.e., what is the expected correlated genetic response in his daughters). If a sire is selected that is one phenotypic SD above the mean $\left(\sigma=17.99 \mathrm{~cm}^{2}\right)$ for pelvic area, the expected corresponding change in his daughter's calving ease score using Equation [1] is a decrease of .03 of a score for calving ease and a decrease of .01 for incidence of calving difficulty. These results, combined with predicted increases in daughter pelvic area, suggest selecting sires based on increased pelvic area will have little effect on calving ease scores of daughters. Cook et al. (1993) also found that increasing yearling pelvic area in replacement females failed to reduce the incidence of dystocia in 2-yr-old heifers, a result also reported by Naazie et al. (1989), who found that pelvic area explained only .2\% of the variation in factors affecting calving difficulty in three lines of synthetic beef heifers. They suggested that a threshold exists for pelvic area such that pelvic areas larger than a certain threshold will not be a useful indicator of problems at calving. This is the basis of the calf birth weight: yearling pelvic area ratio proposed by Deutscher (1989) whereby ratios above 2 would supposedly result in no calving difficulty. Alternatively, Cook et al. (1993) found choosing a sire based on birth weight EPD would be the best tool for reducing dystocia in 2-yr-old heifers.

In conclusion, selecting sires based on increased yearling pelvic area will lead to slight increases in pelvic area in his daughters. However, the increase in pelvic area will not translate into much of a reduction in calving ease scores or incidence of calving difficulty in his daughters.

\section{Implications}

Heritability estimates of pelvic width, pelvic height, and pelvic area of 320-d males and females indicate genetic change can be achieved for these traits by selection. Genetic correlations between pelvic measurements of males and females were large and positive (.61) but should be considered different traits in males and females. A substantial improvement in calving ease scores is not likely if sires are selected for increased yearling pelvic areas.

\section{Literature Cited}

Anderson, K. J., J. S. Brinks, and D. G. LeFever. 1991. Genetic aspects of traits measured prior to calving in beef heifers. J. Anim. Sci. 69(Suppl.):206 (Abstr.).

Bellows, R. A., R. B. Gibson, D. C. Anderson, and R. E. Short. 1971. Precalving body size and pelvic relationships in Hereford heifers. J. Anim. Sci. 33:455.

Benyshek, L., L., and D. E. Little. 1982. Estimates of genetic and phenotypic parameters associated with pelvic area in Simmental cattle. J. Anim. Sci. 54:258.

Boldman, K. G., and L. D. Van Vleck. 1991. Derivative-free restricted maximum likelihood estimation in animal models with a sparse matrix solver. J. Dairy Sci. 74:4337.

Brinks, J. S. 1987. Genetic aspects of calving ease. Proc. Range Beef Cow Symp. X, Cheyenne, WY.

Cook, B. R., M. W. Tess, and D. D. Kress. 1993. Effects of selection strategies using heifer pelvic area and sire birth weight expected progeny difference on dystocia in first-calf heifers. J. Anim. Sci. 71:602.

Cubas, A. C., P. J. Berger, and M. H. Healey. 1991. Genetic parameters for calving ease and survival at birth in Angus field data. J. Anim. Sci. 69:3952.

Deutscher, G. H. 1989. Pelvic measurements of heifers and bulls for reducing dystocia. Proc. Beef Improvement Fed. p 22. Nashville, TN.

George, A., J. Liu, and E. Ng. 1980. User Guide for SPARSPAK: Waterloo Sparse Linear Equation Package. CS-78-30. Dep. Comput. Sci., Univ. Waterloo, Waterloo, ON, CAN.

Green, R. D., J. S. Brinks, and D. G. LeFever. 1986. Some genetic aspects of pelvic measurements in beef cattle. Colorado State Univ. Beef Progress Rep. p 58.

Green, R. D., J. S. Brinks, and D. G. LeFever. 1988. Genetic characterization of pelvic measures in beef cattle: Heritabilities, genetic correlations and breed differences. J. Anim. Sci. 66: 2842.

Gregory, K. E., L. V. Cundiff, and R. M. Koch. 1991. Breed effects and heterosis in advanced generations of composite populations for preweaning traits of beef cattle. J. Anim. Sci. 69:947. 
Holzer, A.L.J., and W. Schlote. 1984. Investigations on interior pelvic size of Simmental heifers. J. Anim. Sci. 59(Suppl. 1):174 (Abstr.).

Laster, D. B. 1974. Factors affecting pelvic size and dystocia in beef cattle. J. Anim. Sci. 38:496.

Meyer, K. 1988a. DFREML - a set of programs to estimate variance components under an individual animal model. J. Dairy Sci. 71(Suppl. 2):33.

Meyer, K. 1988b. DFREML programs to estimate variance components for individual animal models by restricted maximum likelihood. User notes, Edinburgh Univ., Scotland.

Meyer, K. 1989. Restricted maximum likelihood to estimate variance components for animal models with several random effects using a derivative-free algorithm. Genet. Sel. Evol. 21:317.

Meyer, K. 1991. Estimating variances and covariances for multivariate animal models by restricted maximum likelihood. Genet. Sel. Evol. 23:67.

Morrison, D. G., W. D. Williamson, and P. E. Humes. 1986. Estimates of heritabilities and correlations of traits associated with pelvic area in beef cattle. J. Anim. Sci. 63:432.
Naazie, A., M. M. Makarechian, and R. T. Berg. 1989. Factors influencing calving difficulty in beef heifers. J. Anim. Sci. 67: 3243.

Naazie, A., M. Makarechian, and R. T. Berg. 1991. Genetic, phenotypic, and environmental parameter estimates of calving difficulty, weight, and measures of pelvic size in beef heifers. J. Anim. Sci. 69:4793.

Nelson, T. C., R. E. Short, J. J. Urick, and W. L. Reynolds. 1986. Heritabilities and genetic correlations of growth and reproductive measurements in Hereford bulls. J. Anim. Sci. 63:409.

Nelder, J. A., and R. Mead. 1965. A simplex method for function minimization. Comput. J. 7:147.

Neville, W. E., Jr., J. B. Smith, B. G. Mullinix, Jr., and W. C. McCormick. 1978. Relationships between pelvic dimensions, between pelvic dimensions and hip height and estimates of heritabilities. J. Anim. Sci. 47:1089.

Press, W. H., B. P. Flannery, S. A. Teukolsky, and W. T. Vetterling. 1986. Numerical recipes. Cambridge University Press, Cambridge, MA.

Price, T. D., and J. N. Wiltbank. 1978. Dystocia in cattle. A review and implications. Theriogenology 9:221. 